\title{
EDITORIAL
}

\section{Hot-Lot Equivalent of Publishing-The IMMERSION SPECIAL SECTION}

In semiconductor production, there are super-highpriority lots that are supposed to run nonstop. The total run time should be very close to the absolute processing time. The special section on immersion lithography in this issue is the journal equivalent of a wafer hot lot. After observing the eager attendance at the immersion presentations at the SPIE 2003 Microlithography Symposium in March, Bill Arnold and I thought that publishing a special section on immersion before the 2004 Microlithography Symposium would be very desirable for the readers of this journal. It would also be a great service for the authors to publish their findings at a record-breaking pace. Bill said he would give it a try and serve as the guest editor. What a try it was! We pulled out all the stops to make it happen. Authors were documenting their results fervently. Reviewers were doing their best to meet the deadlines without compromising publication quality. I learned of the reviewers' quality work firsthand, because I was fortunate enough to have contributed two articles and co-authored a third. In such matters, I left the editorial decisions completely to Bill, like setting up a blind trust to avoid conflict of interest. He also asked me to serve in his role for papers from his company.

Like always, the reviewers are the unsung heroes. I am very impressed with their professional and selfless attitude. The authors also faced very interesting challenges. They had done exciting work and were eager to publish their findings. On the other hand, the work was still going on and was getting more and more exciting everyday. There was a conflict between trying to put in the latest results and having the paper miss the deadline. There may also have been a publication approval delay that the author had to go through in his or her company. I am glad thirteen of them made it to the deadline. The other papers, including one of mine, will be published in the April issue. Needless to say, without a dedicated guest editor and his experience with hot lots, this special section would not have happened in time.

In view of this, a Technology Update subgroup was created for this special section. The papers in this Technology Update subgroup were prepared as full-length articles and went through the same review process as the rest of the papers in this special section. However, we put a higher priority on timeliness and filling gaps in the content of the entire section, rather than thoroughness of content in each subgroup paper.

No semiconductor manufacturer is contented with the turnaround time of their super hot lot. They always find ways to break their best record. Likewise, we will continue to shorten our publication cycle time to make the papers ever more timely while still upholding the quality.

Happy reading!

\section{Burn J. Lin Editor-in-Chief}

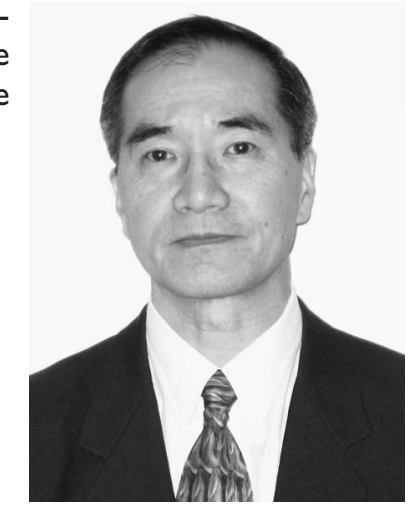

